\title{
Transition Narratives, Priming Events and Reproductive Processes in Lives of Black Families Living in Poverty
}

William Corsaro' Katherine Rosier"

Indiana University Bloomington (IU), Bloomington/IN-United States of America "Central Michigan University (CMU), MountPleasant/MI-United States of America

\begin{abstract}
Transition Narratives, Priming Events and Reproductive Processes in Lives of Black Families Living in Poverty ${ }^{1}$. This paper reports on a three-year ethnography of nine Black families living in poverty. Viewing socialization as a process of interpretative reproduction, the paper examines the language and communicative styles in various local cultures in which the families are embedded. These communicative styles are crucial for understanding routine activities in which parents and children confront the demanding socio-economic structures and circumstances of their daily lives. Micro-analyses of in-depth interviews and naturally occurring interaction in the home, community, and schools generates detailed narratives of the young children's transitions from the family into the school and the wider community.
\end{abstract}

Keywords: Transition Narratives. Priming Events. Black Families.

RESUMO - Narrativas de Transição, Eventos Priming, Processos Reprodutivos nas Vidas das Famílias Negras que vivem na Pobreza. Este artigo relata uma etnografia de três anos com nove famílias negras que vivem na pobreza. Vendo a socialização como um processo de reprodução interpretativa, o artigo examina a linguagem e os estilos comunicativos em várias culturas locais nas quais as famílias estão inseridas. Esses estilos comunicativos são cruciais para compreender as atividades rotineiras em que pais e filhos enfrentam as exigentes estruturas e circunstâncias socioeconômicas de suas vidas diárias. Microanálises de entrevistas em profundidade e interação natural em casa, comunidade e escolas geram narrativas detalhadas das transições das crianças pequenas da família para a escola e para a comunidade em geral.

Palavras-chave: Narrativas de Transição. Eventos Priming. Famílias Negras.

Educação \& Realidade, Porto Alegre, v. 44, n. 2, e88353, 2019.

http://dx.doi.org/10.1590/2175-623688353 
Transition Narratives, Priming Events and Reproductive Processes in Lives...

\section{Introduction}

In research over a number of years we have developed an approach to children's socialization that we have referred to as interpretive reproduction (Corsaro, 1992; 2018; Corsaro; Molinari; Rosier, 2002; Corsaro; Molinari, 2005). This approach differs from traditional theories of human development and socialization in several ways. First, we place special emphasis on language and children's participation in everyday cultural routines. As Ochs has argued, language is central for children's socialization both as a "[...] symbolic system that encodes local social and cultural structure" and as a "[...] tool for establishing (i.e., maintaining, creating) social and psychological realities" (Ochs, 1988, p. 210). These dual aspects of language as a symbolic system and as tool of cultural production are "[...] deeply embedded and instrumental in the accomplishment of concrete routines of social life" (Schieffelin, 1990, p. 19). The habitual, taken-for-granted character of everyday routines provides actors with the security of belonging to a social group. On the other hand, this very predictability empowers routines, providing actors with basic frameworks (Goffman, 1974) within which they can produce, display, and interpret sociocultural knowledge.

Second, the interpretive approach extends traditional theories of socialization which view development as the child's linear progression from immaturity to adult competence. From our interpretive perspective the cultural-developmental process is not linear but reproductive. It is reproductive in that what children do with adults and other children involves the use, refinement, and transformation of cultural resources (see Corsaro, 1992; 2018). In this process of interpretive reproduction, children become a part of adult culture - that is contribute to its reproduction - through their negotiations with adults and their creation, with other children, of a series of peer cultures. Thus, socialization is not merely a matter of acquiring culture at the level of the individual child but also a collective process of innovative or interpretive reproduction.

Central to the interpretive perspective is the documentation of key transitions in children's lives. The most appropriate method for such documentation is comparative, longitudinal ethnography. Such ethnographies capture ongoing productive-reproductive processes in children's lives as they move from the family to other social institutions and how children negotiate these transitions in a number of embedded local cultures such as the family, school and peer group. In this paper we draw from interview and observational materials collected in a three year ethnography of nine Black families living in poverty to examine everyday occurrences which draw attention to coming changes in the children's lives. We refer to these everyday experiences as priming events because they involve activities in which children, by their very participation, attend prospectively to ongoing or anticipated changes in their lives (Corsaro; Molinari, 2000; 2005). Priming events normally involve a combination of cognitive, behavioral, and emotional elements. In this paper we focus primarily on behavior and emotional elements, 
most especially the language and communicative styles parents, teachers, and children employ in their participation in priming events that are normally embedded in everyday cultural routines in the family, classroom, and peer group.

\section{Ethnographic Context and Data}

The project on which this paper is based began as one component of a larger, comparative study that examines preschool children's peer cultures in three settings: an Italian nursery school, a private upper middle class American developmental learning center, and an American Head Start center (see Corsaro, 1994; 2018; Corsaro; Molinari; Rosier, 2002; Corsaro; Rosier, 2002; Rosier, 2000). The current research originated from our earlier ethnography of peer culture in the Head Start center. This study, like our earlier work (Corsaro, 1994; Corsaro; Rosier 1992) involved careful field entry and acceptance by the children and teachers, several months of participant observation, and the collection of field notes and audiovisual recordings of representative episodes of peer and teacher-student interaction.

The Head Start center was located in a large Midwestern city. Head Start income eligibility regulations require that the great majority of participants be from low-income homes. In the classrooms we studied, all of the teachers and all but one of the children were Black ${ }^{2}$, reflecting the population of their inner-city environment.

During participant observation at the center, we were fascinated by the children's incorporation of many issues and themes relevant to their families' economic status into their play and peer interaction. These and other observations convinced us that our understanding of the social worlds of the children would be greatly enhanced by completing interviews with their parents and observing in their homes and communities. We also felt that our research in the center had provided us with a strong and unique foundation from which to begin a longitudinal study of family socialization processes. Thus, we initiated an intensive study of a small sample of families whose children attended the Head Start center. The purpose of this study was to examine the strategies that these families employ, and the obstacles that they face, as their children make the transition from the home, to preschool, and on to elementary school (see Rosier, 2000).

Nine of the ten Head Start mothers we contacted agreed to taperecorded interviews that were conducted in their homes during summer 1990. At that time, each of the mothers had a five year old child expected to begin kindergarten in the fall. Our sample contains mothers who vary greatly in their age, education, and employment history. Although all but one has some history of welfare receipt, only one mother is a young, single parent with no formal employment history who has received government aid (at that time what was called Aid For Dependent Children in the US) since the birth of her oldest child. There are a variety of family types included in the sample: one nuclear family household, one step 
Transition Narratives, Priming Events and Reproductive Processes in Lives...

family, four households composed of a single or separated mother and her children, and three other homes in which unmarried mothers and their children live with other adults - both relatives and non-kin ${ }^{3}$.

In addition to requesting demographic information, our openended interviews encouraged the respondents to talk extensively about their families' circumstances and their children's daily lives. The mothers were gracious and candid in response to our inquiries, and the first set of interviews provided us with a wealth of information about the families. Encouraged by the mothers' willingness to share their experiences, we have maintained regular contact with these families as the children have moved into the early elementary grades. Since the end of the children's Head Start year, we have completed four sets of intensive, open-ended interviews with the mothers over a three year period. We also made informal observations in their homes and communities, joining them for dinner or spending time with the children as they went about their daily activities. Finally, we interviewed the children's kindergarten teachers in the spring, 1991 and first grade teachers one year later. We also carried out some limited observations in several of the children's first grade classrooms.

We have a unique set of longitudinal data that captures the day-today lives of these families. In this paper we focus on the identification and analysis of priming events and parents' perceptions and evaluation of their children's successes and problems in this important transition from the family to formal schooling. We first examine priming events in the family and then go on to consider such events in teacher directed and peer activities in the Head Start classrooms.

\section{Priming Events in the Family}

The mothers involved in this study believed that educational success begins at home, and parents must prepare children for schooling in positive and inspiring ways. In our interviews, all the mothers repeatedly stressed the importance of their children doing well in school and at least obtaining high school diplomas. They viewed education as vital for children's attainment of satisfying and productive lives, and most expressed both regret over choices they made in the past regarding their own education and concern that their children not repeat these mistakes. Their efforts to encourage the children's motivation and achievement emerged from both prospective and retrospective thinking as well as from assessments of present realities.

We first examine the mothers' efforts to prepare and motivate the children for challenges of formal schooling. These strategies include both instruction in basic skills and attempts to instill a high valuation of education in the children. Second, we look at mothers' efforts to prepare children for peer and neighborhood influences that they fear may hinder their children's academic careers. In this case, mothers' efforts are focused primarily on encouraging attitudes and values in their children that will help them to withstand these potential future pressures. 


\section{Drawing Attention to and Preparing for the Challenge of Formal Schooling}

In earlier work (Corsaro; Rosier, 2002; Rosier, 2000; Rosier; Corsaro, 1993) we discussed the mothers' in-home educational activities prior to and during their children's transition into formal schooling. Throughout the summer between the children's Head Start and kindergarten years, for example, all the mothers reported that they regularly engaged their child in educational activities, and several insisted time devoted each day to such activities as writing ABC's and numbers, doing simple calculations, drawing and coloring, and reading with parents and siblings. One mother constructed numerous home-made materials and regularly engaged her children in matching and number games. Educational toys or workbooks, as well as educational television such as Sesame Street and Nickelodeon programs, were also important parts of most children's routines during this transitional period. These activities apparently paid off - when we interviewed the kindergarten teachers near the end of the 1990-1991 school year, all reported the children were performing at or, in most cases, above the average level of their classmates.

In addition to emphasizing such activities and encouraging the development of concrete skills and knowledge, the mothers reported that they often forecasted coming changes in their children's lives prior to their entry into kindergarten, and also the following year when they would begin attending school for a full day in first grade. One mother reported a story about her son who she had constantly reminded that he would attend kindergarten when he was five years old. It seems that the day after his fifth birthday in May he awoke, dressed and announced to his mother: Well I'm ready to go to kinnygarten, Mamma, walk me to kinnygarten. When she told him he had to wait until autumn, he reportedly said: But I don't wanna go to Head Start no more, I'm five years old! (Rosier, 2000; Corsaro, 2018).

The mothers also continually stressed both the practical and moral value of academic pursuits. Children have been encouraged to view their present activities as foundations for the future. This forwardlooking perspective is nicely illustrated by one mother's tactic of capitalizing on her son's admiration of sports personalities to encourage perseverance and diligence in repetitive tasks. In our first interview with Amy she reported that when Jeremiah complained about having to write his ABC's everyday, she responded that: Air Jordan [reference to basketball star Michael Jordan] practice basketball everyday, the same thing day in and day out. In a later interview, Amy recounted a similar conversation with her son:

I said, Jeremiah, what you wanna be when you grow up?
He said, well I wanna be like Air Jordan. I said, well, Air
Jordan has an education. I bet you Air Jordan didn't play
in school [...] if you wants to be like him - I'm not talkin'
basketball-wise, that will come in time - now, you have to

Educação \& Realidade, Porto Alegre, v. 44, n. 2, e88353, 2019. 
Transition Narratives, Priming Events and Reproductive Processes in Lives...

work on your studies. You know, like knowin' your ABC's, knowin' them when you see 'em [...] you have to practice every day, every day. You think Air just shoot a basketball once and said, well, I'm gonna be great? And never picked up a basketball again? No, he practice every day. Now you gonna have to practice [...] (Corsaro; Rosier, 2002; Rosier, 2000).

Throughout the remainder of this section, much of our focus will be on one particular mother and family whose experiences and words best illustrate how the mothers involved in this study stress not only such practical rewards of schooling, but also tend to take a more philosophical approach to the benefits of educational achievement. Rhonda was 23 years old and the single parent of three pre-school children when we first met her in the summer of 1990. She lived with her children, mother and brother in the same apartment in a small public housing project that she had lived in since she was a pre-teenager. In our first interview, Rhonda described the manner in which she talks to her daughter Cymira about education and learning:

With Cymira I deal with steps. OK, you're the child on the first step tryin' to make it to the third step. OK, a child on the first step is under pressure to make it to the third step and their whole life they're being told - Look, if you want that, you gotta do that, OK? And I press Cymira - to get to that second and third step, you're gonna have to learn. Then she'll say to me-Mamma, is it all learnin'? Life is school, your entire life is goin' to be school. Am I gonna go to school all the time? Every day you wake up and step out your front door, you're at school, you're gonna learn somethin' whether good or bad, pretty or ugly, you're gonna learn somethin'. And its best to stand up there with your spine straight up, and learn this, Cymira [...]. We, as low income people compared to people who have where you know - Chargers, that's what I call 'em, Chargers, we can't charge it, we have to buy it with what we got [...]. And if you ever want to be one of the chargers, you gotta learn somethin', its all learnin', life is learnin' - like my Grandmother always say [laugh], Ain't a day goes by you don't learn something.

Rhonda perhaps best sums up her beliefs about education as the foundation for a dignified life when she again evokes her own grandmother's words: Why get on your knees all your life, when you can stand up and make this walk, stand tall and proud to make this walk?. Rhonda and other mothers routinely drew on such metaphoric imagery when discussing the topic of education with their children. The rich oral tradition that the women apparently grew up with and are now passing along to their children is clearly an important resource that helps them to both make sense of the often chaotic world they live in and to instill values in their children (Rosier, 2000). When Rhonda repeated her grandmother's words, as she does with great conviction, emotion, and regularity, it is clear that such folk wisdom is a vital source of inspiration and pride for her. It is also clear when she employs this colorful language that she is attempting to pass on feelings of pride and dignity to her daughter, and inspire Cymira to achieve all she can. 
Although the mothers mentioned a variety of specific advantages they believe schooling can provide (e.g., more satisfying work, more money, better character, and the ability to help their families and communities), the following summation of the value of education spoken by Marissa when her oldest child was a kindergarten student, is shared by all the mothers:

When they get to a certain age, and they think they know it all, and they're out of your control, you can't really do nothin' but tell 'em, you know, sit down and tell 'em that school will help you get through life.

Despite their children's young age, references to expected upcoming rebelliousness and trials of adolescence are frequent, and the mothers' talk often betrayed considerable anxiety and feelings of impotency in the face of monumental obstacles they feared their children would encounter.

\section{Preparing for Future Transitions: temptation, responsibility, and decency in challenging environments}

All the mothers expressed fears about negative aspects of the neighborhoods and peer cultures that their children may soon (or already do) confront. In line with their anxiety about what lies ahead, they have often mentioned priming events or activities that draw their children's attention to these influences. Primarily, the mothers have focused on first, restricting children's activities and second, encouraging attitudes and values that will help them to withstand future pressures (Corsaro; Molinari, 2000; Rosier, 2000).

Throughout our several years of acquaintance with these families, the mothers continually voiced their concerns about: truancy; drugs; shootings and other violence; gangs; and early sexual activity and pregnancy. In fact, only a few minutes into the first interview with Amy, she expressed both her apprehensions about their neighborhood and the rules she enforced to protect her five-year-old son from exposure to its dangerous features. When asked what Jeremiah needed to learn and to know in order to get along well and be successful in his community, Amy replied:

The first thing, especially in this community where I live, you have to be very particular about who you play with. You need to protect your child like this, because there's gang problems over here bad. Now, like up these stairs right here [which lead to a small public housing project], I do not allow him to go up here, 'cause there's lots of trouble, and I do not allow him to play with anybody who lives up there... he don't interact with any in the community, because I just don't trust 'em, the community, this community that is. 'Cause there's so many problems here.

Other mothers echoed Amy's concerns in this earliest round of interviews, and described similar restrictions on activities. For example, Annette said she and her husband preferred that their six children (aged 1-7 in 1990) play only with one another. While she occasionally 
Transition Narratives, Priming Events and Reproductive Processes in Lives...

allowed other neighborhood children to visit, at no time were the children permitted to leave the house or front porch unaccompanied by an adult. Another mother, Samantha, reported that she instructed her son Ramone to just get up on the front porch, when he saw a group on teenagers coming down the street because you never know, kids have access to everything now, guns, and I don't want to be a statistic.

Such concerns increasingly preoccupied the mothers as their children have moved from preschool into the early elementary grades. In most cases, mothers who formerly placed severe limits on their children's freedom of movement in the neighborhoods responded to the children's growing maturity and bids for independence by loosening these restrictions somewhat. While granting greater freedom is viewed as developmentally appropriate, it adds to the anxiety these mothers feel in response to perceived negative environmental pressures (Rosier, 2000).

As children age and behavioral restrictions are relaxed, what other options do parents have to help their children meet the challenges that confront them? The mothers agreed that their children's best defense against the drugs, violence, and other peer pressures they encounter must be a set of attitudes and values that include high selfesteem, achievement motivation, and a strong sense of morality and decency (see Anderson 1994). While they placed less emphasis on behavioral rules and more on values as their children mature, the moral foundations were steadily constructed throughout the children's lives.

All of these families lived in low-income neighborhoods characterized by high rates of school dropout and unemployment, but the level of observable poverty and violence varied considerably. Only Rhonda's family lived in a public housing complex, and it was here that gang activity, drugs, and violence was most readily apparent. Concerns about the dangers of the housing complex was central in all interviews with Rhonda. For example, in our second interview, she noted how commonplace guns and violence had become in her neighborhood:

Gunshots are - its like wakin' up and lookin' outside the window [...]. Over here, a shot fired is like - hmmm, you count your kids, and you know whew! - wipe the sweat off, and continue walkin'.

Perhaps somewhat ironically, Rhonda was among the least restrictive of her children's activities, allowing them to make and visit numerous friends in the complex, and to play outside for extended periods with limited supervision. While she clearly recognized dangers and negative influences that her children were regularly exposed to, she realistically concluded that:

Where I live at, the things that are happenin', the only way that I could not show her [daughter Cymira] - I would have to blindfold her and walk her through everything. I would have to walk her through life with this blindfold not to show her.

Rhonda had explained in our first interview that while she wanted to encourage non-judgmental attitudes in her children (I want'em to 
know that drug addicts and people like that are people, too), at the same time, she stressed that: Momma's not like that. I live in that environment, but we're not like that...We can beat this.

Rhonda and other mothers struggle daily in a battle with their environment for their children. While they recognize the power of their adversary and at times express somewhat fatalistic views about their chances of success, Rhonda's comment above illustrates their refusal to allow it to define their children's lives. Instead, they continually encouraged their children to aim high, and not allow anyone or anything to limit their aspirations. Rhonda reported the following exchange she had with her daughter:

She wants to be a doctor, a policeman, a lawyer or a nurse. She says: 'can I be president?' I says, 'well, we still fightin' that issue'. 'Well, I can be that'. I say, 'Yes you can, yes you can'. 'Can I make furniture?' 'yes you can'.

From our first interview with Rhonda, it was clear that Cymira is granted near-adult status when she is present during adult conversation. Rhonda has never reacted negatively to Cymira's interruptions. In fact, Cymira's interruptions were viewed as relevant and informative contributions. Further, in some instances mother and daughter collaborated in the telling of an event, with Rhonda altering her story at times to reflect Cymira's corrections or elaborations. Rhonda noted with pride that Cymira will correct you when you're wrong [...] If an adult is wrong, she's gonna let you know - no, you're wrong, this is how it go. At one point, she recounted a humorous event where Cymira had confronted a male friend of Rhonda's about behavior the child knew her mother did not condone. Although Rhonda had chosen to ignore this behavior and was embarrassed by Cymira's action, she allowed Cymira to speak her mind, and she concluded: if there's somethin' that you just have to say, say it. Don't hold nothin' in or back. From every indication, Cymira's intellect, competence, and 'right' to participate in family affairs is fundamentally respected by her mother.

Rhonda indicated that she believes that Cymira should be well-informed about adult things, especially about relationships between men and women (also see Rosier; Corsaro, 1993; Rosier, 2000). It is in this area that Rhonda explicitly said that she wants Cymira to be street-wise. She drew on her own experiences as a teenager, describing herself as a $n a$ ive 16-year-old whose innocence was exploited by Cymira's father, and vows her daughter will be more sophisticated, assertive, and above all, more certain of her self-worth than she was herself. This attitude of selfrespect and self-reliance is one that Rhonda would like to see applied not only to her daughter's future relationships with male peers, but also to Cymira's on-again-off-again relationship with her father: I want her to believe in herself, and then if she wants to believe in her Daddy? Hey, go ahead with it.

At first glance, it may appear that Rhonda's socialization strategies were contradictory. On the one hand, she accepts her children's exposure to harsh realities of their inner-city environment, and she actively strives to encourage them to be knowledgeable, competent, and some- 
Transition Narratives, Priming Events and Reproductive Processes in Lives...

what hardened and cynical actors in this arena. On the other hand, she has developed a repertoire of routine priming activities that encouraged Cymira and her brothers to view themselves as somehow set apart from others in their community.

Such seemingly conflicting emphases suggest great complexity in these children's lives that may be difficult for them to interpret and integrate. Yet managing such contradictions is a special burden and, indeed, a special talent of Black families in America. The literature on Black family life and socialization patterns is replete with references to similar apparently contradictory goals and strategies of parents attempting to raise healthy, happy, productive, and safe Black children (e.g., Anderson, 1994; Boykin; Toms, 1985; Collins, 1991; Holliday, 1985; Ogbu 1988). Collins (1991), for example, argues that such inconsistencies can perhaps be best understood as parents' efforts to balance needs to ensure children's physical survival on the one hand, while at the same time encouraging them to transcend the many obstacles and boundaries they must confront.

\section{Priming Events in the Headstart Classroom}

In the Head Start classroom priming events were interwoven in the fabric of everyday activities in structured and unstructured teacher-child interactions in the school culture and in the activities of the children's peer culture. We discuss briefly a few examples from each of the local cultures.

\section{Priming Events in the Head Start Curriculum}

Most of the teacher directed activities at Head Start involved cognitive and language drills that were carried out in strict accordance with written instructions in curriculum materials. These drills all involved variants of questions from teachers which were to be answered in complete sentences by the children. A major problem with such drills was that they normally involved teachers asking Wh-questions (e.g., Where is the bird?) in which a normally perfectly acceptable answer like In the tree or On the branch were deemed incorrect by the teachers without explanation because they were not full sentences (i.e., The bird is in the tree). A much better way to elicit evidence of children's abilities to speak in full sentences would have been them to tell a story or recount a past event. As a result of this limitation of the curriculum the children sometimes became confused, believing that there could only be one correct answer to such questions. This belief often lead to the children's them becoming quite anxious about volunteering responses even when they knew the right answer. Something that continued when the children went on to kindergarten and elementary school (see Rosier, 2000).

In addition to language drills, the curriculum also included cognitive and perceptual tasks and again teachers were instructed only to note when an answer was correct or incorrect and not give reasons why some answers were not acceptable. This procedure also caused a great 
deal of anxiety for the children especially in some cognitive tasks where children were not provided enough contextual information to make accurate judgments. Consider the following example.

\section{Example 1: stand in front of the longest line}

The teacher had the children sit as a group facing her. Between the teacher and the group of children were three lines (strios of tape attached to the floor) of differing lengths. The researcher (Corsaro) sat next to the children. (see Figure 1). After consulting the lesson plan in a book, the teacher asked one of the children (Jerome) to: stand in front of the longest line. The researcher immediately thought that there was some ambiguity to this question because (at least to him) standing at point 1 or 2 (given the point of reference) could be seen as correct. Jerome moved quickly to the longest line, straddled it for a second, and then stood at point 1 . The teacher said that was incorrect and asked Jerome to sit back down with the group. She then called on Alysha. Alysha quickly walked up and stood at point 2. To the researcher's surprise, the teacher said that Alysha's response was incorrect and that she must return to the group and sit down. At this point a general sigh went up among the group of children. The researcher was also confused about what the teacher thought the right answer was. She then called on three more students. The first two tried points 1 and 2 respectively, and were again told that they were incorrect. The third student, Zena, stood in back of the shortest line which was, of course, also incorrect. The researcher had by this time decided that point 3 or 4 must be the right answer. However, given that there was no arrow or any kind of point of reference, he was not sure which answer the teacher (or more importantly the lesson plan in the book) considered to be correct. The teacher asked all the children, and they all failed to get the right answer. Finally, she asked the researcher to come up and display the correct answer. He did so with some caution, selecting point 3 in the end. She said this was correct, and praised the researcher's choice. The teacher then moved on to a new task (Stand in back of the shortest line), and from this point most of the children produced the correct (or prescribed correct by the lesson plan) answer. However, they often proceeded with a great deal of caution and anxiety in making their decisions. 


\section{Figure 1 - Stand in Front of the Longest Line}

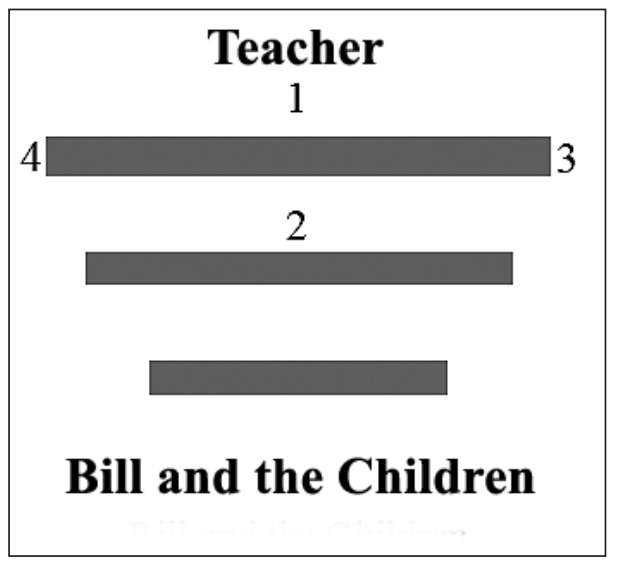

Source: Elaborated by the authors.

Our point here is not to criticize the teacher. She faithfully followed the lesson plan laid out in the book as prescribed. Later when we pointed out the ambiguity to her, she agreed that it could be confusing. However, she noted that it was important to stick with the lesson plan and to elicit eventually a correct response for the children to model (see Corsaro; Molinari; Rosier, 2002; Corsaro; Rosier, 2002).

Furthermore, despite these negative features, the drills do prepare the children for the participant structure format (with teacher questioning and selecting particular children for a specific answer) that is so common in American kindergarten and first grade classroom (see Mehan, 1979). For this reason the teacher directed drills can be seen as priming events. However, while contributing to needed knowledge of participant structure of future classroom lessons, we have found that these priming events fostered an anxiety and a perfectionist attitude in the classroom performance of some of the children in kindergarten and first grade (see Corsaro; Rosier, 2002).

Other features of the curriculum that can be seen as priming events are projects and field trips that draw attention to the children's community - its history, organizations, activities, leaders, neighborhoods, families and workers. In these projects children not only learn about their community, but also about themselves and their constantly changing place in the community as developing members.

For example, there were weeklong projects on the family, community helpers (including neighborhood walks, and visits to a fire station, post office and a department store), and leaders in the African American community like Dr. Martin Luther King, Jr. During the week before the celebration of the holiday commemorating Dr. King's birthday, a teacher read a story that recreated his life. The story was quite detailed with pictures and it contained discussion of King's childhood, youth, experiences with segregation, his activism against racism, and ultimately his assassination. The children listened very attentively and 
occasionally made comments like I know about him, My Mommy told me about that, etc. At the end of the story the children asked a number of interesting questions. Having already experienced several recent field trips, Steven asked if we could go to see King's boyhood home that was pictured in the story. The teacher responded that maybe Steven could go sometime, but that it was in Atlanta and too far for the class to go. But Darren said: No, you shouldn't go because you'll get killed. The teacher said that Steven would not be killed and that it all happened a long time ago. Another girl, Denise, then asked if we could go to Martin Luther King's funeral. The teacher smiled and said no. But before she could go on, Anne asked if Martin Luther King was going to have a birthday party. The teacher then said that Martin Luther King died a number of years ago so we could not attend his funeral, but we could celebrate his birthday with a party of our own during the holiday from school (see Corsaro; Rosier, 2002).

Although the children's comments and questions reveal temporal confusion about events in Martin Luther King Jr's life, they clearly reveal that the children were relating the story to their own lives and attempting to tie it to the school projects and field trips. This type of retrospective-prospective thinking is a key outcome of priming events as children link information from the past to their current and future lives (Corsaro; Molinari, 2000).

Other priming events were embedded in field trips to different parts of the community. One such trip involved a walk around the neighborhood where the school was located. On the walk the teachers pointed out community helpers in line with the theme of that particular week in the school curriculum. At one point we waited at a bus stop and the teacher discussed the service bus drivers and cab drivers perform for the community. After a few minutes a bus arrived and came to halt alongside us. When the driver opened the door the teacher told him that the children were learning about community helpers and wanted to thank him for his work. All the children cheered and the bus driver smiled and honked his horn as he pulled away. Later as we continued our walk we saw some men collecting garbage and the same scenario was repeated.

These experiences got the children talking about other community helpers (e.g., mail carriers, fire fighters etc.) as we headed back to the school. However, this trip into the community drew the children's attention to some of the negative elements of the neighborhood as well. As we stopped to read the sign for a barbecue restaurant, a number of children pointed to the bars on the window and broken glass on the sidewalk. Further along our route we encountered several men standing outside a convenience store drinking from bottles enclosed in paper bags. The teacher hurried us along and did not respond to the children's comments and questions about the men.

These examples demonstrate the complexity of priming activities at the Head Start center. In both the structured classroom lessons and the projects and field trips, the preparatory or prospective power of the 
Transition Narratives, Priming Events and Reproductive Processes in Lives...

priming events was tempered by the challenging circumstances of these children's lives. The classroom drills provided the children with needed practice for accommodating to a discourse participant structure that will dominate in elementary school but is so different than discourse in the family and peer group (see Heath, 1983). However, at the same time the drills created an uncertainty and anxiety in the children regarding their ability to display their knowledge and skills. Similarly the priming events embedded in field trips and related projects drew the children's attention to both positive and negative aspects of their community. The children prospected to their increasing participation and involvement in a community with positive role models and in the life of the streets with all its problems, dangers, and enticements.

\section{Priming Events in Peer Culture}

Of the many types of priming events that occurred in peer interaction, we examine those related to the children production of dramatic role play. In dramatic play in which children take on family or occupational roles, children reproduce the complex social relations of adults in their lives and, in turn, prospect about their eventual movement into and enactment of these adult social positions. In the Head Start center we frequently observed the children engaged in such role play in which they pretended to be employees in fast-food establishments, harried single mothers frustrated by their children's constant demands and misbehavior, parents taking sick baby dolls to the clinic, and police ordering suspected drug dealers against the wall to be searched.

We were struck by the high drama, exacting detail, and complexity of the Head Start children's role play as compared with the role play of American upper middle class children (see Corsaro, 1993; 1994; 2018). Here we have time to consider one short sequence of family role involving two girls, Debra and Zena, pretending to be mothers having a phone conversation. This sequence begins as Debra dials the toy telephone and initiates a conversation with Zena:

\section{Example 2}

78 D: What you been doin'?

79 Z: Hah. Cookin'. Now I need to go to the grocery store.

80 D: I got to take my kids to the party store, they told me//

81 I said -

$82 \mathrm{Z}$ : //(My kids-- )//my kids want me to take them to the 84 park.

85 D: What?

$86 \mathrm{Z}$ : My kids told me to take them to the park, and then, and

87 then the bus had to come and get 'em. That's gonna be a 88 long walk for to here! And then the bus would have to 89 come and get us!

90 D: Well, we have to wait for transfers, then I have to buy

91 groceries, we have to buy some groceries. And um //( )

$92 \mathrm{Z}$ : //Guess where my kids told me to take them? // To the

93 store. When the bus comes by (my kids waitin' for it). I

94 don't got time to do that. 
In this segment the girls, through their use of what Goodwin (1990) terms format tying (the systematic use of the surface structure of speech for orderly sequencing in informal talk), establish shared agreement regarding a general topic for their telephone talk. We see that in response to Debra's question in line 78, Zena notes she is cooking but needs to go to the grocery store. Debra ties her turn at 80 to Zena's previous turn by noting that: I got to take my kids to the party store (a smaller store for buying things like milk, bread and snacks). Zena then picks up on Debra's introduction of kids (82), using the same exact phrase my kids and noting that they want to be taken to the park. Zena expands her description at line 86 by introducing the information that the kids will have to take the bus because it is too far to walk to the park. At line 90, Debra continues the orderly sequencing by semantically tying her turn to Zena's earlier mention of the bus by stressing the requirement of having to wait for transfers. Finally, in lines 92-94 Zena ties her turn to Debra's prior turn by noting that she does not have time to be waiting for the bus.

The girls' skillful building of coherent discourse through the repetition of syntactic features of prior turns and the semantic linkage of developing ideas or information in the discourse is important because it enables the collaborative construction of a shared topic: Problems of parenting in poverty. Here several key aspects of the content of the sequence are important. It is not just that the mothers (here animated by the children) have to do everyday chores like shopping, their children expect them to provide a number of additional services. However, the children's discourse reveals that it is not easy to meet such expectations if you do not have a car and must deal with a limited and time consuming bus service.

We can see then that dramatic role play of this type is an important priming activity in that its very production enables the children to practice their developing language, cognitive and social skills and to prospect and anticipate their movement in the adult world. In this sense, dramatic role play contributes to the children's development of a set of predispositions (Bourdieu, 1977) through which they confront the objective structures or circumstances of their present and future lives.

\section{Conclusion}

We have examined priming events in the lives of several American Black families living in poverty. We looked at the nature and significance of priming events in the family as revealed in in-depth interviews with mothers and observations in the home. We also discussed priming events that occurred regularly in teacher-child and peer interaction in a Head Start center the children from these families attended. We demonstrated how the children's participation in these priming events prepare them for present and future challenges of formal schooling. We have also argued, more generally, for the importance of such priming

Educação \& Realidade, Porto Alegre, v. 44, n. 2, e88353, 2019. 
Transition Narratives, Priming Events and Reproductive Processes in Lives...

experiences for the children's anticipating, securing, and transforming their lives as they move from childhood toward preadolescence.

A key finding was the complex, multi-layered effects of the priming events in the lives of these children. Given the harsh and challenging demands of their political and economic circumstances, the priming experiences of these children draw their attention to: (1) a set of dichotomous value orientations including hard work and perseverance versus play and fun, personal responsibility versus dependence, community versus personal gain; and (2) the sober recognition of daunting challenges they face in embracing these values and realizing their consequences Priming experiences can certainly help individuals to confront, adapt to, and sometimes transform the objective structures or circumstances of their daily lives. However, the ultimate power of unequal and discriminate structures cannot be matched by the mere espousal of positive values and morals.

Anderson (1994) has recently argued that the low-income Black families he came to know through an ethnographic study of Philadelphia neighborhoods also dealt daily with the contradictory pushes and pulls of two distinct orientations that organized social life in the community. He described two poles of value orientation - decent and street - and argued that although the majority of homes in the community reflected mainstream decent values, knowledge of the code of the streets was necessary for operating in public. Anderson argues that because the street-oriented minority is able to dominate and control public spaces, even parents with a strong decency orientation find it necessary to familiarize their children with the code and expectations of the streets, and to encourage them to be competent players. Even young children must be tutored in toughness, and "[...] looking capable of taking care of oneself as a form of self-defense is a dominant theme among both street-oriented and decent adults who worry about the safety of their children" (Anderson, 1994, p. 86). Knowledge of the code of honor and respect, and a presentation of self that includes lack of fear and exaggerated toughness, are essential for young people hoping to negotiate successfully their volatile neighborhood environments. In such contexts, the priming experiences of these children seem not inconsistent or contradictory, but rather reasoned responses to the multitude of complex situations and challenges that they face or will soon confront.

Received on November 22, 2018 Approved March 11, 2019

\section{Notes}

1 This article is part of the Thematic Section, Childhood and Education of EthnicRacial Relations, organized by Renato Noguera (Universidade Federal Rural do Rio de Janeiro), Míghian Danae Ferreira Nunes (Universidade da Integração Internacional da Lusofonia Afro-Brasileira), Luciana Pires Alves (Universidade do Estado do Rio de Janeiro) and Nancy Lamenza Sholl da Silva (Universidade Federal Fluminense). 
2 Throughout this article, we use Black rather than African American or some other term. We recognize there is some controversy over this issue. However, our choice of terminology reflects our respondents' own usage and identification.

3 Prior to participation in this study, these mother had already shown their concern about their children's development and education by enrolling them in the Head Start program. Therefore, they may be more motivated than others in similar circumstances. Although this potential bias exist, this sample is appropriate for capturing the enormity of the task that even resourceful poverty families face in helping their children in the important transition from home to formal schooling.

\section{References}

ANDERSON, Elijah. The Code of the Streets. The Atlantic Monthly, Boston, v. 273, n. 5, p. 81-94, 1994.

BOURDIEU, Pierre; PASSERON, Jean-Claude. Reproduction in Education, Society, and Culture. Beverly Hills: Sage, 1977.

BOYKIN, A. Wade; TOMS; Forrest D. Black Child Socialization: a conceptual framework. In: MCADOO, Harriet Pipes; MCADOO, John Lewis. Black Children: social, educational, and parental environments. Newbury Park: Sage, 1985. P. 33-51.

COLLINS, Patricia Hill. The Meaning of Motherhood in Black Culture and Black Mother-Daughter Relationships. In: BELL-SCOTT, Patricia; GUY-SHEFTALL, Beverly; ROYSTER, Jacqueline Jones; SIMS-WOOD, Janet; DECOSTA-WILLIS, Miriam; FULTZ, Lucie. Double Stitch: black women write about mothers and daughters. Boston: Beacon Press, 1991. P. 42-60.

CORSARO, William Arnold. Interpretive Reproduction in Children's Peer Cultures. Social Psychology Quarterly, Thousand Oaks, v. 55, p. 160-77, 1992.

CORSARO, William Arnold. Interpretive Reproduction in Children's Role Play. Childhood, London, v. 1, p. 64-73, 1993.

CORSARO, William Arnold. Discussion, Debate and Friendship: peer discourse in nursery schools in the United States and Italy. Sociology of Education, Washington, D.C, v. 67, p. 1-26, 1994.

CORSARO, William Arnold. The Sociology of Childhood. 5. ed. Thousand Oaks: Sage, 2018.

CORSARO, William Arnold; MOLINARI, Luisa. Priming Events and Italian Children's Transition from Preschool to Elementary School: representations and action. Social Psychology Quarterly, Thousand Oaks, v. 63, p. 16-33, 2000.

CORSARO, William Arnold; MOLINARI, Luisa. I Compagni: understanding children's transition from preschool to elementary school. New York: Teacher's College Press, 2005.

CORSARO, William Arnold; MOLINARI, Luisa; ROSIER, Katherine Brown. Zena and Carlotta: transition narratives and early education in the United States and Italy. Human Development, Basel, v. 45, p. 323-348, 2002.

CORSARO, William Arnold; ROSIER, Katherine Brown. Documenting Productive-Reproductive Processes in Children's Lives: transition narratives of a black family living in poverty. In: CORSARO, William Arnold; MILLER, Peggy Miller. Interpretive Approaches to Children's Socialization. San Francisco: JosseyBass, 1992. P. 5-23. 
Transition Narratives, Priming Events and Reproductive Processes in Lives...

CORSARO, William Arnold; ROSIER, Katherine Brown. Priming Events, Autonomy, and Agency in Low Income African-American Children's Transition from Home to School. In: EDWARDS, Rosalind (Ed.). Children, Home and School regulation, autonomy or connection? New York: Routledge, 2002. P. 138-154.

GOFFMAN, Erving. Frame Analysis. New York: Harper \& Row, 1974.

GOODWIN, Marjorie Harness. He-Said-She-Said: talk as social organization among black children. Bloomington: Indiana University Press, 1990.

HEATH, Shirley Brice. Ways with Words: language, life and work in communities and classrooms. New York: Cambridge University Press, 1983.

HOLLIDAY, Bertha Garrett. Developmental Imperatives of Social Ecologies: lessons learned from black children. In: MCADOO, Harriet Pipes; MCADOO, John Lewis (Ed.). Black Children: social, educational, and parental environments. Newbury Park: Sage, 1985. P. 53-69.

MEHAN, Hugh. Learning Lessons. Cambridge: Harvard University Press, 1979.

OCHS, Elinor. Culture and Language Development: language acquisition and language socialization in a Samoan village. New York: Cambridge University Press, 1988.

OGBU, John U. Black Education: a cultural-ecological perspective. In: MCADOO, Harriet Pipes (Ed.). Black Families. 2. ed. Newbury Park: Sage, 1988. P. 169-83.

ROSIER, Katherine Brown. Mothering Inner City Children: the early school years. New Brunswick: Rutgers University Press, 2000.

ROSIER, Katherine Brown; CORSARO, William Arnold. Competent Parents, Complex Lives: managing parenthood in poverty. Journal of Contemporary Ethnography, Thousand Oaks, v. 22, p. 171-204, 1993.

SCHIEFFELIN, Bambi. The Give and Take of Everyday Life: language socialization of Kaluli children. New York: Cambridge University Press, 1990.

William Arnold Corsaro holds a PhD in Sociology from the University of North Carolina, Chapel Hill (1974). He is currently a full professor of the Indiana University Sociology Department, Blommington. Among his research interests, we highlight the Sociology of Childhood, Ethnography and Sociology of Education.

ORCID: http://orcid.org/0000-0001-6789-8204

E-mail: wacorsaro@gmail.com

Katherine Brown Rosier is currently Associate Professor of Sociology at Central Michigan University. Her current interests are focused on children's identity issues, and the decline of children's freedom in post-9/11 America. ORCID: http://orcid.org/0000-0003-1819-4694

E-mail: rosielkb@cmich.edu

This is an open-access article distributed under the terms of the Creative Commons Attribution License 4.0 International. Available at: <http://creativecommons.org/licenses/by/4.0>. 